\title{
Cranial Osteology of Meiglyptini (Aves: Piciformes: Picidae)
}

\author{
Reginaldo José Donatelli \\ Laboratory of Ornithology, Department of Biological Sciences, Sciences College, São Paulo State University (UNESP), \\ Caixa Postal 473, 17001-970 Bauru, SP, Brazil \\ Correspondence should be addressed to Reginaldo José Donatelli, rjdonat@yahoo.com.br
}

Received 18 July 2011; Revised 22 September 2011; Accepted 22 September 2011

Academic Editor: Friedrich Paulsen

Copyright ( $) 2012$ Reginaldo José Donatelli. This is an open access article distributed under the Creative Commons Attribution License, which permits unrestricted use, distribution, and reproduction in any medium, provided the original work is properly cited.

\begin{abstract}
The Meiglyptini comprise eight species grouped into three genera: Meiglyptes and Mulleripicus, with three species each, and Hemicircus, with two species. The aim of the present study was to describe the cranial osteology of six species and three genera of Meiglyptini and to compare them to each other, as well as with other species of woodpeckers and other bird groups. The cranial osteology varied among the investigated species, but the most markedly distinct characteristics were: (1) a frontal overhang is only observed in the middle portion of the frontale of H. concretus; (2) the Proc. zygomaticus and suprameaticus are thick and long in species of the genus Mulleripicus, but short in other species; (3) the Pes pterygoidei is relatively larger in species of the genus Mulleripicus, while it is narrow, thin and relatively smaller in species of the genus Meiglyptes and indistinct in H. concretus; (4) the bony projection of the ectethmoidale is relatively short and thin in species of Mulleripicus and more developed in H. concretus. It appears that the greatest structural complexity of the cranial osteology is associated with the birds' diet, with the frugivorous $H$. concretus being markedly different from the insectivorous species.
\end{abstract}

\section{Introduction}

Woodpeckers have been investigated scientifically for over a century. These birds are notable for their colour, size, foraging mode, nest-building behaviour, instrumental signals, and the way they climb vertical surfaces. Interestingly, many of the behavioural patterns of woodpeckers are closely related to their anatomical features. Thus, these aspects cannot be dissociated in a study [1].

The Meiglyptini comprise three genera of Old World woodpeckers: Meiglyptes and Mulleripicus, with three species each, and Hemicircus, with two species [2]. These species are all arboreal and feed mainly upon the larvae and eggs of insects, ants and secondarily termites, beetles, caterpillars, and other arthropods. There is also a frugivorous species in this group, $H$. concretus.

The foraging modes vary among these woodpeckers, irrespective of food type. The Meiglyptini primarily employ gleaning, with probing and tapping being used secondarily; excavating and tonguing are less common.

The aim of the present study was to describe and compare the mandibular apparatus of several species of Meiglyptini and perform a morphofunctional analysis of the complexity of this apparatus, relating it with the species' foraging mode. Specifically, the following questions were addressed:

Are the foraging mode and the structure of the mandibular apparatus related among the Meiglyptini?; and is it possible to establish any relationship between form and function based on structural differences between the jaw apparatus and the foraging modes? Thus, there are at least two hypotheses to be considered: (1) there is no relationship between the structural complexity of the mandibular apparatus in Meiglyptini and the foraging mode, and (2) there is a relationship between the structure of the mandibular apparatus and the foraging mode in Meiglyptini.

\section{Materials}

In this study, I described the osteological characters of the skull of 15 specimens of Meiglyptini belonging to three genera and six species. The specimens are housed at the National Museum of Natural History (USNM), Smithsonian Institution, Washington DC, USA, the Museum Zoologicum 


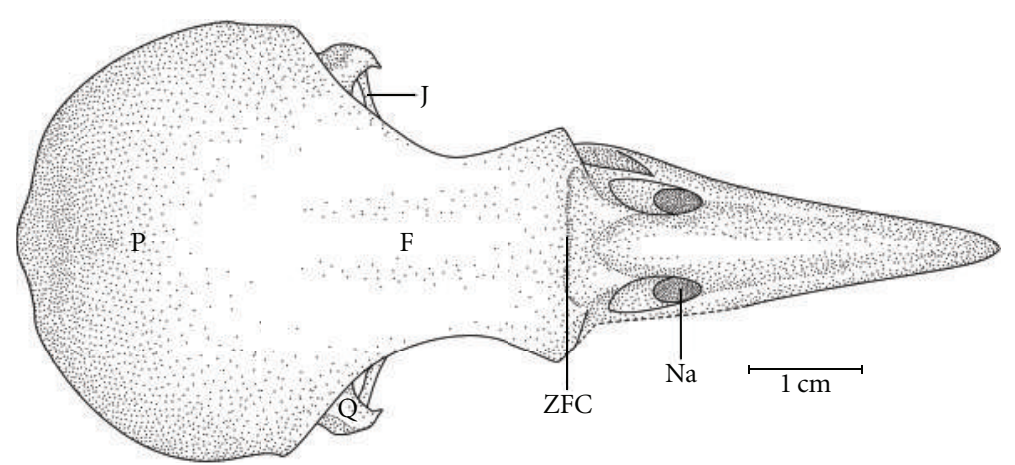

FIGURE 1: Dorsal view of the skull of Meiglyptes tristis. F: frontal region; J: jugal arch; NA: nostril; P: parietal region; Q: quadrate bone; ZFC: craniofacial flexion zone.

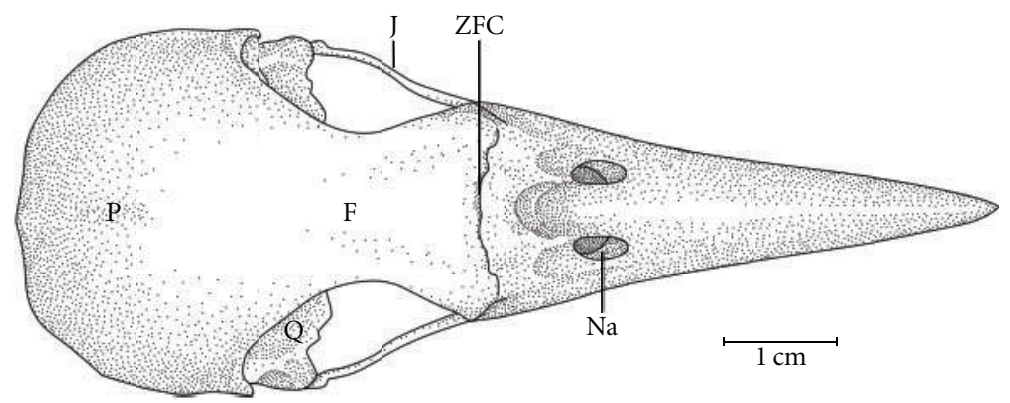

FIGURE 2: Dorsal view of the skull of Meiglyptes tukki. F: frontal region; J: jugal arch; NA: nostril; P: parietal region; Q: quadrate bone; ZFC: craniofacial flexion zone.

Bogoriense (MZB), Indonesian Institute of Sciences (LIPI), and the Natural History Museum of the Indonesian Institute of Sciences, Indonesia.

Bellow is a list of the species investigated after Winkler and Christie [2], museum abbreviations and the relative numbers of specimens in the collections. All specimens preserved in $70 \%$ ethanol were from the Museum Zoologicum Bogoriense, Indonesian Institute of Sciences (LIPI), whereas the others were osteological material: Hemicircus concretus (Temminck, 1821) LIPI MZB.Skt 125 Hc1; LIPI MZB.SKT 126 HC2; Meiglyptes tristis (Horsfield, 1821) LIPI MZB.Skt Mtr1 123; MZB.Skt Mtr2 124; USNM 292,228 0 $0^{7}$; Meiglyptes tukki (Lesson, 1839) LIPI MZB.Skt Mtu1 121; MZB.Skt Mtk1 122; USNM 489,269 o; Mulleripicus pulverulentus (Temminck, 1826) LIPI MZB.Skt Mp1 127; MZB.Skt 128 Mp2; o USNM 19201, USNM 562,042 क; Mulleripicus fulvus (Quoy and Gaimard, 1830) USNM 491,227 क, USNM 226,191 \%; Mulleripicus funebris (Valenciennes, 1826) $0^{7}$ USNM 489,265.

\section{Methods}

The osteology of the skull and mandible was studied comparatively, described, and drawn using a Zeiss Stemi SV11 stereomicroscope (http://www.zeiss.com/) with magnification ranging from 4 to 66X. M. pulverulentus was used as a reference for comparison of structures. All drawings are accompanied by legends to facilitate the observation of structures.
The nomenclature used to describe the cranial osteology follows the Nomina Anatomica Avium (NAA; $[3,4]$ ). When no reference to a particular structure was available, I used letters and numbers to avoid the unnecessary creation of names. The species nomenclature follows Winkler and Christie [2].

\section{Results}

\subsection{Osteology}

Ossa cranii. The Os frontale (F) articulates rostrally with the Os nasalis through the craniofacial flexion zone (ZFC). This is more evident in M. tristis (Figure 1) and M. tukki (Figure 2) and less in H. concretus, whereas it is indistinguishable in M. pulverulentus. Hemicircus concretus (Figure 3) bears a unique thin bony elevation $(\mathrm{Be})$ at the middle portion of the Os frontale; there is no such elevation in other species. Laterocaudally, the frontal region is connected with the Proc. postorbitalis (PrPO). This process is short, with approximately $1 / 6$ of the length occurring between its origin in the skull and the jugal arch in M. tristis (Figure 4), 1/5 in H. concretus (Figure 3), 1/4 in M. tukki (Figure 5), and $1 / 3$ in M. pulverulentus (Figure 6). The sutura frontolacrimalis is absent, and the Os lacrimale is fusioned with the frontal region in all species.

The Os parietale is expanded laterally approximately twice the length of the lateral expansion of the Os frontale in 


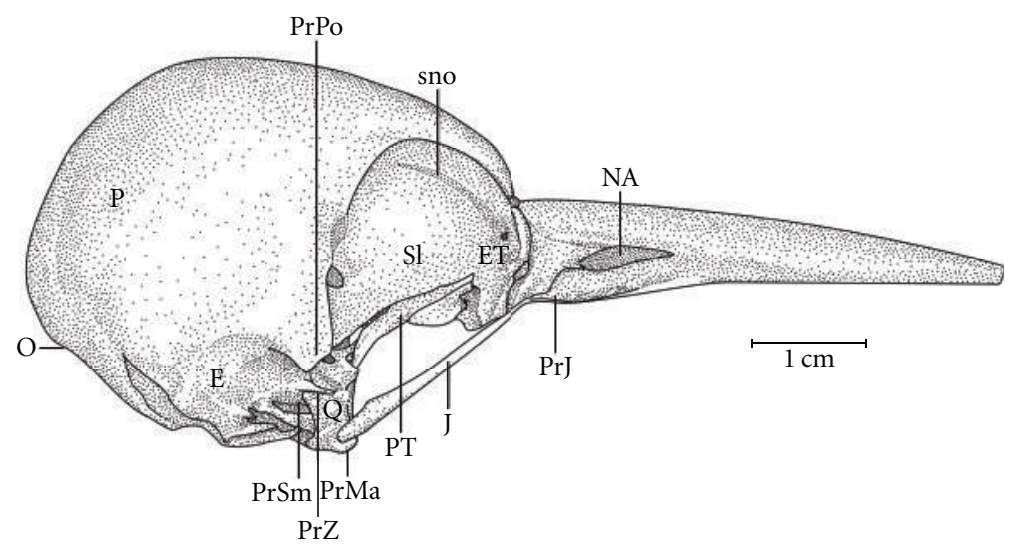

FIGURE 3: Lateral view of the skull of Hemicircus concretus. E: squamosal region; ET: ectethmoid region; J: jugal arch; NA: nostril; P: parietal region; PjJ: jugal projection; PrMA: mandibular process of the quadrate bone; PrZ: zygomatic process; PrPO: postorbital process; PrSm: suprameatic process; PT: pterygoid bone; Q: quadrate bone; SI: interorbital septum; sno: olfactory ridge; O: occiptal region.

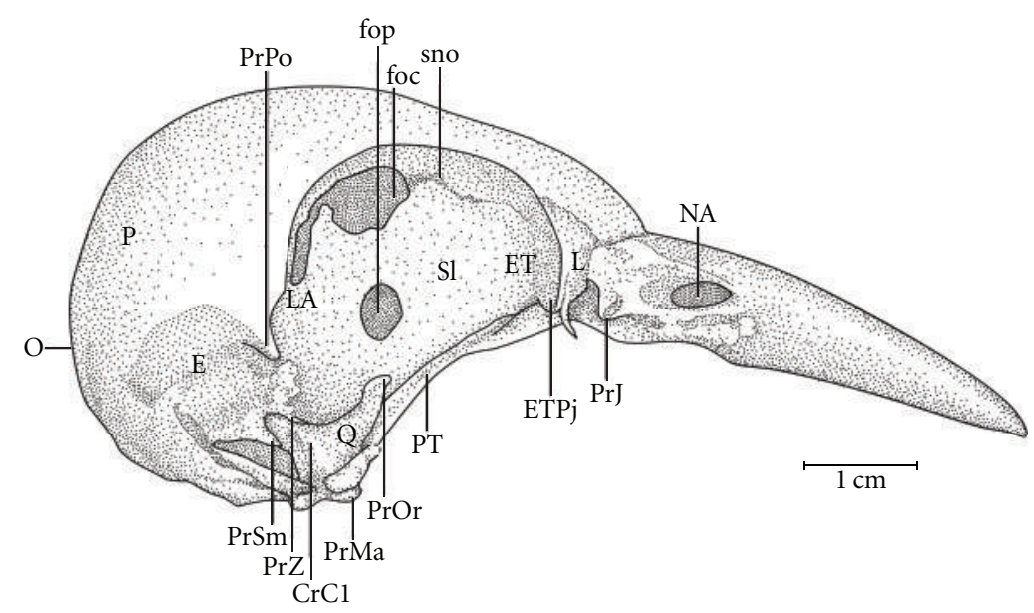

Figure 4: Lateral view of the skull of Meiglyptes tristis. CrC1: C1 crest; E: squamosal region; ET: ectethmoid region; ETPj: ethmoid bony projection; foc: foramen; fop: optical foramen; J: jugal arch; L: lacrimal region; LA: laterosphenoid bone; NA: nostril; P: parietal region; PjJ: jugal projection; PrMa: mandibular process of the quadrate bone; PrOr: orbital process of the quadrate bone; PrPO: postorbital process; PrSm: suprameatic process; PrZ: zygomatic process; PT: pterygoid bone; Q: quadrate bone; SI: interorbital septum; sno: olfactory ridge; O: occiptal region.

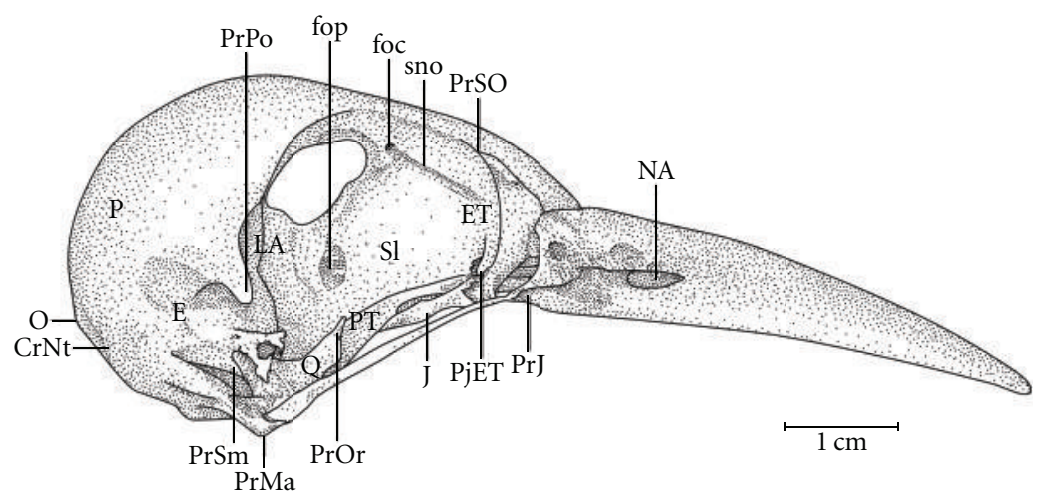

FIGURE 5: Lateral view of the skull of Meiglyptes tukki. CrNt: transverse nuchalis crest; E: squamosal region; ET: ecthetmoid region; PjET: ethmoid bony projection; foc: foramen; fop: optical foramen; J: jugal arch; LA: laterosphenoid bone; NA: nostril; P: parietal region; PjJ: jugal projection; PrMa: mandibular process of the quadrate bone; PrOr: orbital process of the quadrate bone; PrPO: postorbital process; PrSm: suprameatic process; PrZ: zygomatic process; PT: pterygoid bone; Q: quadrate bone; SI: interorbital septum; sno: olfactory ridge; O: occiptal region. 


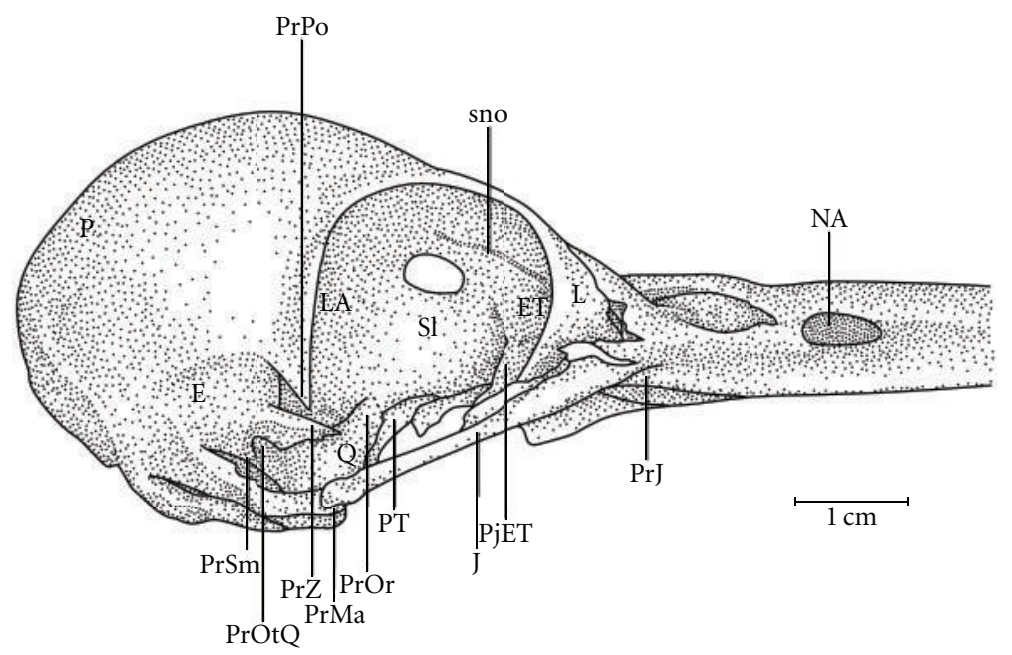

Figure 6: Lateral view of the skull of Mulleripicus pulverulentus. E: squamosal region; ET: ectethmoid region; PjET: ethmoid bony projection; J: jugal arch; L: lacrimal region; LA: aterosphenoid bone; NA: nostril; P: parietal region; PjJ: jugal projection; PrMa: mandibular process of the quadrate bone; PrOr: orbital process of the quadrate bone; PrOtQ: otic process of the quadrate bone; PrPO: postorbital process; PrSm: suprameatic process; PrZ: zygomatic process; PT: pterygoid bone; Q: quadrate bone; SI: interorbital septum; sno: olfactory ridge.

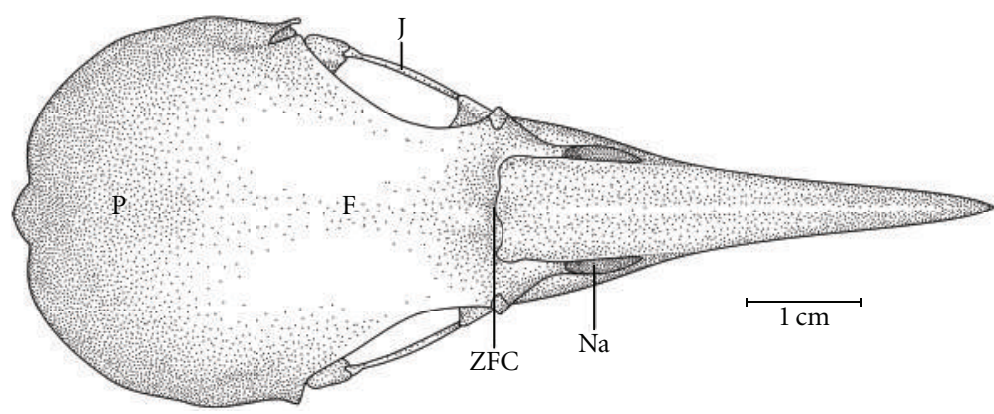

FIGURE 7: Dorsal view of the skull of Hemicircus concretus. F: frontal region; J: jugal arch; NA: nostril; P: parietal region; ZFC: craniofacial flexion zone.

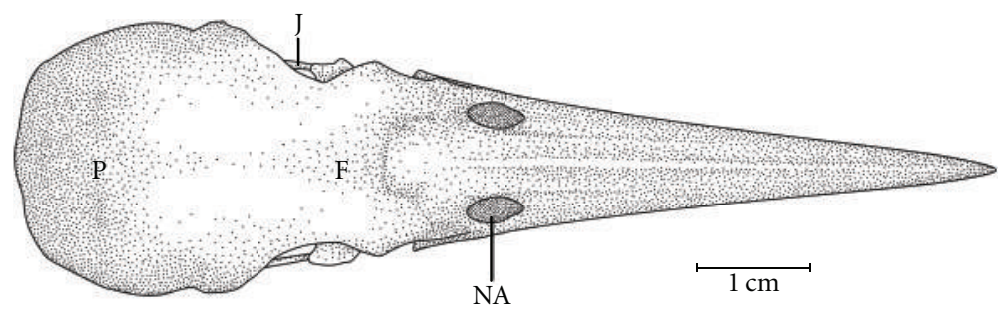

Figure 8: Dorsal view of the skull of Mulleripicus pulverulentus. F: frontal region; J: jugal arch; NA: nostril; P: parietal region.

H. concretus (Figure 7), about 1.5 times in M. pulverulentus (Figure 8), and about 2.5 times in M. tristis (Figure 1) and M. tukki (Figure 2).

The values of these parameters indicate not only the frontale/parietale relationship but also provide the skull dimensions in many species. The Os squamosum is connected anteromedially with the Os laterosphenoidale by the crista laterosphenoidale (CrL-Figure 5) and anterocaudally with the Os frontale by the Proc. postorbitalis. The Fossa temporalis is wider than long in all species.
The Os squamosum is projected rostrally, forming the Proc. zygomaticus (PRZ), which articulates ventrally with the Proc. oticus quadrati and clearly has dorsal, lateral, medial, and ventral faces. This is the region of origin of the aponeurosis of the M. adductor mandibulae externus ventralis and the M. adductor mandibulae externus rostralis lateralis (Donatelli, [5]). The Proc. zygomaticus (Proc. squamosal, [6]) is thick and long in species of the genus Mulleripicus (Figure 6) and short in the other species. The Os squamosum also forms the Proc. suprameaticus (PrSm-Figure 6), and 


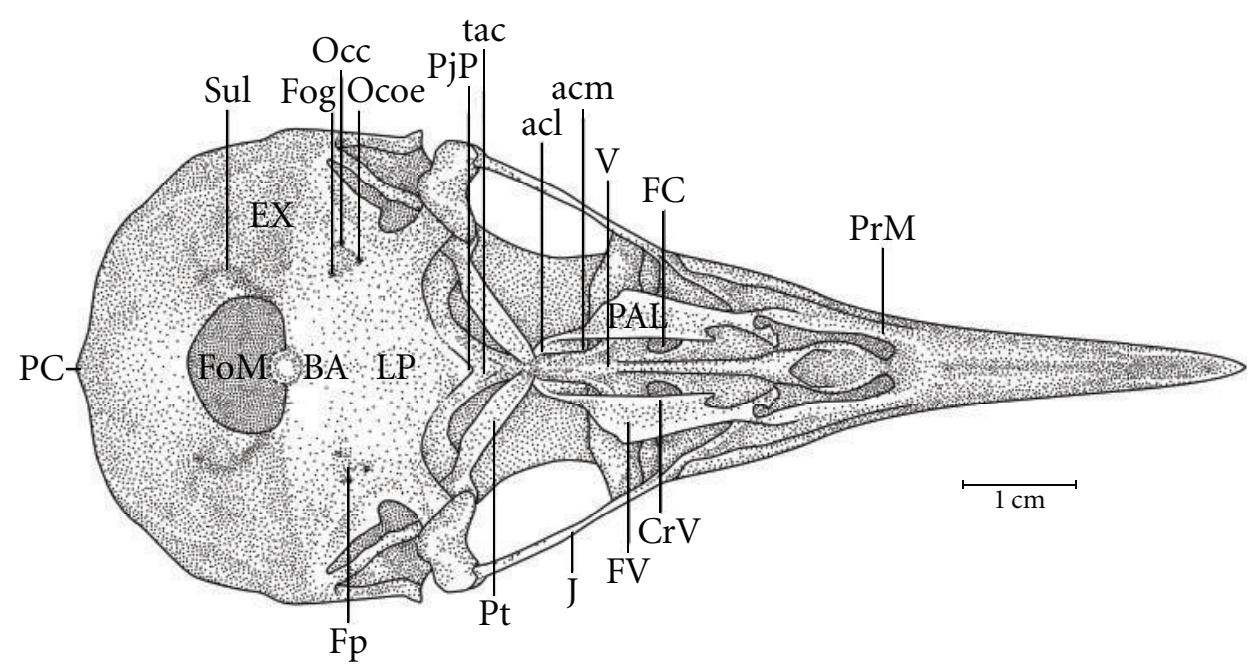

FIGURE 9: Ventral view of the skull of Hemicircus concretus; BA: basioccipital region; CrV: ventral palatine crest; EX: exoccipital region; FC-; Fog-; FoM: foramen magnum; Fp-; FV: ventral fossa; J: jugal arch; LP: lamina parasphenoidalis; Occ-; Ocoe-; PAL: palatine; PC-; PjP: projection of the parasphenoid rostrum; PrM: maxilar process of the palatine; PrPA: paraoccipital process; Pt: pterygoid bone; RP: parasphenoidal rostrum; Sul: intercotylar sulcus; V: vomer; Occ: Ostium canalis carotici; Ocoe: Ostium canalis ophthalmici externus; PC: Proeminentia cerebellaris; Fog: Foramen nervi glossopharyngealis; FC: Fossa choanalis; Fp: Fossa parabasalis.

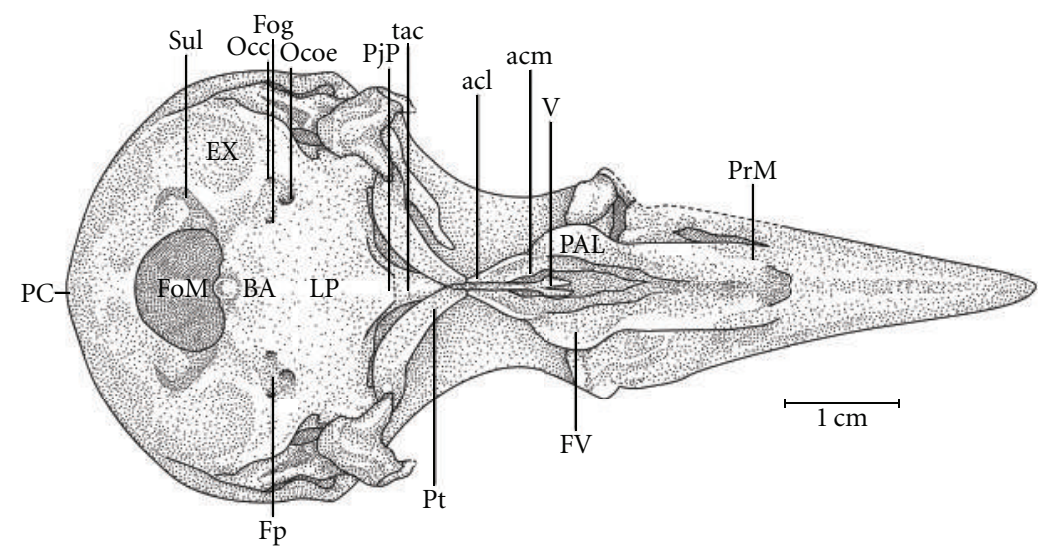

FIGURE 10: Ventral view of the skull of Meiglyptes tristis; BA: basioccipital region; EX: exoccipital region; Fog-; FOM: foramen magnum; Fp-; FV: ventral fossa; LP: lamina parasphenoidalis; Occ-; Ocoe-; PAL: palatine; PC-; PjP: projection of the parasphenoid rostrum; PrM: maxilar process of the palatine; Pt: pterygoid bone; Sul: intercotylar sulcus; V: vomer; Occ: Ostium canalis carotici; Ocoe: Ostium canalis ophthalmici externus; PC: Proeminentia cerebellaris; Fog: Foramen nervi glossopharyngealis; Fp: Fossa parabasalis.

this is present only in species of the genus Mulleripicus (Figure 6).

Ossa faciei. The Os pterygoideum has a well-developed anterior expansion, known as the Pes pterygoideus, which extends rostrally and articulates with the ventral portion of the septum interorbitale, the rostrum parasphenoidale, and the pars palatina. The Pes pterygoideus is observed and well developed in species of Mulleripicus, but it is relatively less developed, thin, and narrow in species of Meiglyptes and absent in $H$. concretus. Posterodorsally to the Os pterygoideum lies the processus dorsalis, which includes the aponeurosis of the M. protractor pterygoidei. This is only present in species of Mulleripicus.
In the middle portion of the Os palatinum lies the fossa choanalis (FC), which is delimited by the crista ventralis $(\mathrm{CrV})$, forming a gap. This gap varies in size among the species studied. It is relatively wider in $H$. concretus (Figure 9), decreases in width in species of Meiglyptes (Figure 10), and is relatively narrow in species of Mulleripicus (Figure 11), in which the Os palatinum is curved caudally. Between the cristae ventralis et lateralis lies the fossa ventralis (FV), which is distinct and deep in $M$. tristis (Figure 10), relatively deep and shallow in species of Mulleripicus (Figure 11), and shallow in M. tukki (Figure 12) and $H$. concretus (Figure 9). This is an important region because it is the origin of the aponeurosis and muscle fibres of the M. pterygoideus ventralis (Donatelli, [5]). 
The Os laterosphenoidale lies caudally to the facies orbitales. It is connected laterally with the Os squamosum by the crista laterosphenoidale (CrL-Figure 5), where the aponeurosis of the $M$. adductor mandibulae externus caudalis medialis originates (Donatelli, [5]). This crest is apparent only in species of the genus Mulleripicus and in M. tukki (Figure 5). It is common to observe a swelling in the connection between the crista laterosphenoidale and the septum interorbitale in all species. The nerve foramen lies ventrolaterally.

The Os ectethmoidale has a bony projection (ETPjFigures 4-6) reaching the dorsal surface of the arcus jugalis, though without fusion. The projection is relatively more apparent in $M$. tristis (Figure 4) than in other species, but it is more developed in $H$. concretus (Figure 3 ). It assumes a triangular shape in M. tukki (Figure 5). In Mulleripicus (Figure 6), the projection is relatively short and thin upon the arcus jugalis.

The Os quadratum has a corpus quadrati that connects with the proc. oticus quadrati (PrOtQ), proc. orbitalis, and proc. mandibularis. The proc. oticus quadrati articulates dorsally with the Os squamosum by the ventral surface of the proc. zygomaticus (PRZ), which protrudes dorsally upon the proc. oticus quadrati in the species of Mulleripicus (Figure 6). This process is relatively shorter in H. concretus and M. tukki. In species of Mulleripicus, there is a greater distance between the proc. orbitalis quadrati and the posterior portion of the Os laterosphenoidale. In the proc. oticus quadrati, a small C1 crest $(\mathrm{C} 1 \mathrm{Cr})$ can be observed in all species but represented in M. tristis (Figure 4), which originates from the aponeurosis of the $M$. adductor mandibulae externus caudalis lateralis (Donatelli, [5]). The proc. orbitalis quadrati (PrOr-Figures 46) protrudes anteromedially from the corpus quadrati. This is a short process, but its form varies greatly among species. In general, it is slender and has a length equivalent to two thirds of the length of the Os pterygoideus, which lies medially. The condylus medialis is usually the most developed, compared to other condyles, as observed in most species, and this structure is relatively more developed in M. tristis, in which it acquires a protruding and pointed shape. The condylus caudalis is an extension of the condylus lateralis in all species.

The maxilla is formed by the fusion of the Os premaxillare, maxillare, and nasale. It presents approximately half the total length of the skull in most species, except in species of Mulleripicus (Figure 8), in which it measures approximately $65 \%$ of the total length of the skull.

Ossa Mandibulae. The pars symphisialis mandibulae (Psi) is short and measures slightly more than one third of the total length of the mandible only in species of Meiglyptes. In M. pulverulentus, the Psi measures approximately $40 \%$ of the total length of the mandible, compared to $45 \%$ in $H$. concretus.In the dorsal region of the mandible lies the proc. pseudocoronoideus 1 (= process of the $M$. adductor mandibulae, [3]). This process is the insertion point of the tendon common to the $M$. adductor mandibulae externus rostralis temporalis and the $M$. adductor mandibulae externus rostralis medialis (Donatelli, [5]). It is indistinct in all species, except $M$. tristis and species of Mulleripicus. Additionally, the proc. pseudocoronoideus 2 is relatively indistinct in all species.
On the pars intermedia, there is a peculiar depression, the fossa lateralis mandibulae, in which the muscle fibres of the $M$. adductor mandibulae externus ventralis are inserted. This region is connected to the posterior portion by the crista caudalis mandibulae. This crest reaches the dorsal Proc. pseudocoronoideus 2.

In the middle portion of the mandible lies the proc. medialis mandibulae (internal jaw process, angular medial process, $[6,7])$, which protrudes dorsomedially. This process varies greatly in length in the woodpeckers studied. This is one of the most important structures for the insertion of muscle fibres and their aponeurosis of the complex of the Os pterygoideum. The tuberculum pseudotemporale, which includes the aponeurosis of the M. pseudotemporalis superficialis, is also noticeable. It is a conspicuous structure in most species, except in $H$. concretus. All species bear a shallow fossa caudalis in the posterior portion of the mandible. This is the insertion point of the muscle fibres of the M. depressor mandibulae.

Some of the structural differences observed in the components of the cranial osteology of the Meiglyptini are noteworthy due to their exclusivity, relative development (being larger or smaller) or unique features present in one group of species within a genus or a species, as follows: (1) there is a thin bony elevation (Be), referred to as the frontal overhang by Bock [8], in the middle portion of the Os frontale in $H$. concretus; (2) the Os parietale is expanded laterally and is equivalent to approximately twice the length of the lateral expansion of the Os frontale in $H$. concretus, 1.5 times in $M$. pulverulentus, and 2.5 times in $M$. tristis and $M$. tukki; (3) the fossa temporalis is wider than long in all species; (4) the proc. zygomaticus is long and thick in species of the genus Mulleripicus and short in the other species; (5) the proc. suprameaticus (PrSM) is apparent only in species of the genus Mulleripicus; (6) the Pes pterygoidei is relatively larger in species of the genus Mulleripicus, relatively smaller, thin, and narrow in species of the genus Meiglyptes, and indistinct in $H$. concretus; (7) the fossa choanalis is relatively wider in $H$. concretus and becomes progressively narrower in species of Meiglyptes and Mulleripicus; (8) the fossa ventralis palatina is deep in $M$. tristis and becomes progressively shallower in Mulleripicus species, M. tukki, and H. concretus; (9) the bony projection of the Os ectethmoidale is relatively short and slender in Mulleripicus species and more developed in $H$. concretus; (10) the condylus medialis is usually the most developed one in all species, and, in $M$. tristis, it is prominent and pointed; (11) the pars symphisialis mandibulae is short and extends for slightly more than $1 / 3$ of total length of the mandible only in species of Meiglyptes for approximately $40 \%$ in M. Pulverulentus, and approximately $45 \%$ in $H$. concretus.

\section{Discussion}

This analysis of the cranial osteological structures of the Meiglyptini elucidated seven important mechanisms of operation of the jaw apparatus: (1) Ossa cranii: frontal overhang, the extension of the Os parietale versus the Os frontale, 


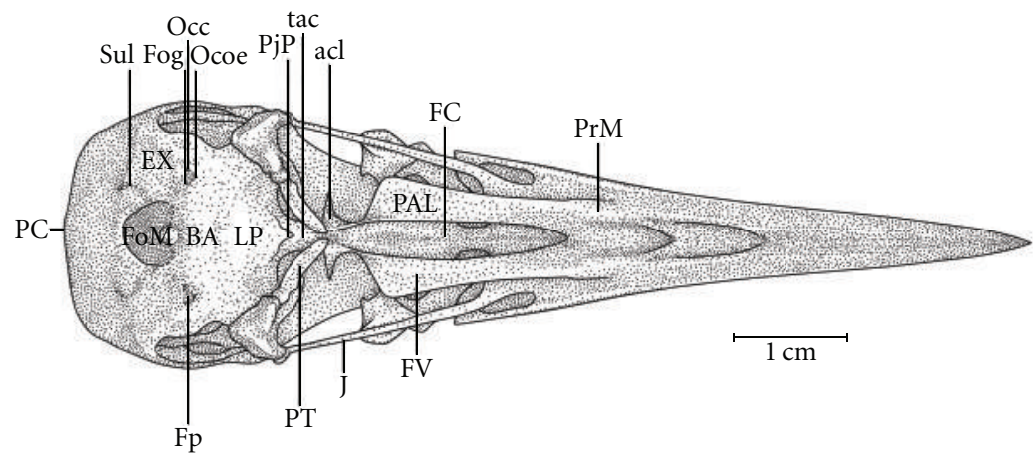

Figure 11: Ventral view of the skull of Mulleripicus pulverulentus; BA: basioccipital region; EX: exoccipital region; Fog-; FOM: foramen magnum; FC-; Fp-; FV: ventral fossa; J: jugal arch; LP: lamina parasphenoidalis; Occ-; Ocoe-; PAL: palatine; PC-; PjP: projection of the parasphenoid rostrum; PrM: maxilar process of the palatine; PT: pterygoid bone; Sul: intercotylar sulcus; V: vomer; Occ: Ostium canalis carotici; Ocoe: Ostium canalis ophthalmici externus; PC: Proeminentia cerebellaris; Fog: Foramen nervi glossopharyngealis; FC: Fossa choanalis; Fp: Fossa parabasalis.

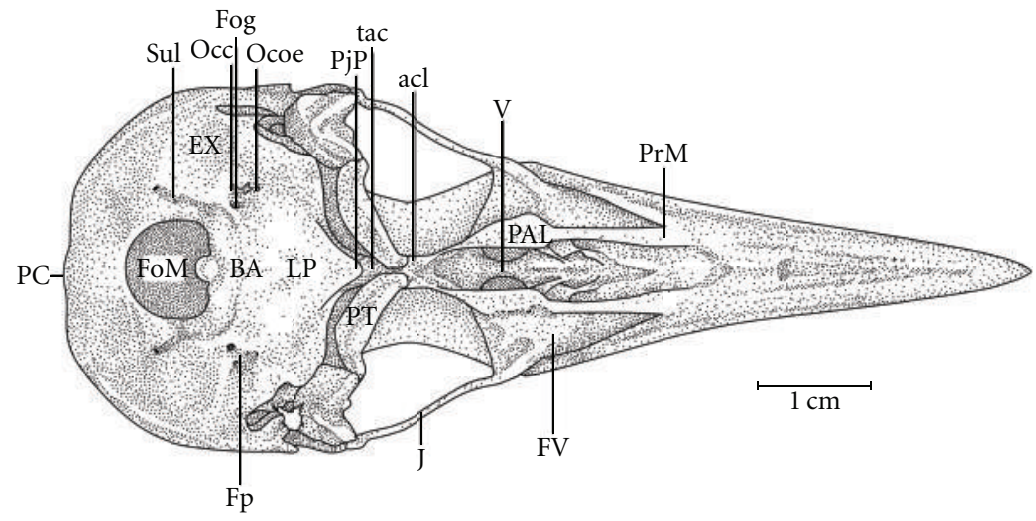

FIGURE 12: Ventral view of the skull of Meiglyptes tukki; BA: basioccipital region; EX: exoccipital region; Fog-; FOM: foramen magnum; FC-; Fp-; FV: ventral fossa; J: jugal arch; LP: lamina parasphenoidalis; Occ-; Ocoe-; PAL: palatine; PC-; PjP: projection of the parasphenoid rostrum; PrM: maxilar process of the palatine; PT: pterygoid bone; Sul: intercotylar sulcus; V: vomer; Occ: Ostium canalis carotici; Ocoe: Ostium canalis ophthalmici externus; PC: Proeminentia cerebellaris; Fog: Foramen nervi glossopharyngealis; FC: Fossa choanalis; Fp: Fossa parabasalis.

fossa temporalis, proc. suprameaticus, and proc. zygomaticus; (2) Ossa faciei: anterior expansion of the Os pterygoideum, Pes pterygoidei, fossa choanalis, fossa ventralis palatine, bony projection of the Os ectethmoidale, and condylus medialis quadrati; (3) Ossa mandibulae: pars symphisialis mandibulae.

$H$. concretus is the only species within the Meiglyptini that presents a bony elevation in the Os frontale, which is known as the frontal overhang [8]. Among the species of woodpeckers studied by Donatelli [1], only Picumnus cirratus exhibited such a structure though it was later found in species of Picus (Donatelli [5]), and it was described in Sphyrapicus varius by Burt [9]. Bock [8] suggested that this structure functions as a "bony stop", preventing an excessive protraction of the maxilla. This mechanism is more important in woodpeckers specialized to obtain food by drumming ("drilling" or "pecking") in trees. However, the great majority of the Meiglyptini (this study), the Picini (Donatelli [5]), and the Neo- and Afrotropical woodpeckers [1] that drum on tree bark exhibit no such structure. Moreover, $H$. concretus does not drum on tree trunks. The main foraging strategy of $H$. concretus is gleaning among the canopy; therefore, it is difficult to explain such a complex structure in this species. This structure seems controversial and deserves a broader study of woodpecker species before a more precise conclusion about its function can be drawn.

The variation of the Os parietale in relation to the Os frontale appears to determine the proportions of the skull in many species. However, I found that the smallest species that investigated $(H$. concretus) did not present the largest expansion, similar to what has been found in other studies on woodpeckers ([1], in prep.) . The strongest relationship was found in intermediate-sized species of Meiglyptes and in species of Hemicircus and Mulleripicus.

The proc. zygomaticus and suprameaticus, which are important insertion points of muscles and the aponeurosis of the $M$. adductor mandibular system, were relatively more developed in larger species (Mulleripicus) and underdeveloped in other species of Meiglyptes and Hemicircus. In other groups of woodpeckers, such processes vary in size and shape, and it is not possible to establish a clear relationship 
between their development and size ([1], in prep.). Jollie [10] suggested that the Os squamosum articulates with the Os quadratum and a short proc. "zygomaticus" in chickens, which was also observed in all species of Picidae studied here. However, the proper term for this should be proc. squamosal and not "zygomaticus" [4], as the term "zygomatic" is characteristic of mammalian skulls.

The anterior expansion of the Os pterygoideum forms the Pes pterygoidei. The length of this process increases in associate with the size of Meiglyptini species, from the largest to the smallest in the order Mulleripicus, Meiglyptes, and Hemicircus. This observation diverges from findings of previous studies (e.g., Donatelli $[1,5]$ ) that found that this structure is well developed and is a unique feature of all woodpeckers. Such a structure was not described in other groups of birds related to the Piciformes, such as the Galbulidae [11] or Coraciiformes [12]. In these birds, the Pes pterygoidei is the insertion point of the fibres of the $M$. pterygoideus dorsalis medialis, which is an important muscle retractor of the upper jaw. Burton [7] described the Pes pterygoidei in the Picidae, Picumninae, and Indicatoridae. The proc. pterygoideus dorsalis [13] is the insertion point of the aponeurosis of the $M$. protractor pterygoideus. This process is conspicuous only in Mulleripicus among the Meiglyptini. In the Picidae (Donatelli [5]), this process is larger in B. rubiginosus and smaller in other species, but always distinct. This process was not mentioned by Burton [7], perhaps because he considered it as only one muscle of the M. protractor quadrati system: the $M$. protractor pterygoidei et quadrati (with insertion in the dorsal portion of the articulation of the pterygoideum-quadratum). Donatelli $[1,5]$ described this muscle as two distinct muscles $(M$. protractor pterygoidei and $M$. protractor quadrati) because they had different origins and insertions. Bock ([14], p. 12) previously called attention to this structure, particularly in woodpeckers.

The M. pterygoideus ventralis medialis, which lies in the fossa ventralis palatine, is very well developed in woodpeckers and represents a powerful retractor of the upper jaw in birds. Gennip [15] is one of the few authors who described this fossa and related it to the origin and development of the M. pterygoideus ventralis medialis. Other authors studying the Columbidae $[16,17]$ did not mention this structure and only related the development of these muscles in species within the family. According to Bock [14], "the mass and shape of the palate are correlated with the size and power of the upper jaw and with the strength of the muscles. Many of the exact details of this correlation must still be ascertained." According to Morioka [18], the deeper the fossa ventralis palatina, the greater the development of the related muscle mass and the greater the power of retraction of the upper jaw. However, he noted that the poorly developed muscle mass in the Apodidae allowed them to close their beak more rapidly, at the expense of a "powerful biting force." Among the woodpeckers studied, this structure is relatively deep and conspicuous only in $M$. tristis, whereas the largest size and structural development of the M. pterygoideus ventralis medialis et lateralis were found in M. pulverulentus. The size and shape of the proc. orbitalis quadrati is prominent in Mulleripicus species relative to other woodpeckers. The associated M. pseudotemporalis profundus is also relatively more developed. Donatelli [5] reported that $B$. rubiginosus had the largest process among the Picini, and the associated muscle was relatively less developed than in other species. As pointed out by Bock [14], the condylus medialis mandibulae is the most developed among the condyles of the Os quadratum. This is similar to what was found in the Meiglyptini, especially in M. tristis, in which the condyle was even more distinguished in shape.

We found clear structural differences in the cranial osteology between the frugivorous $H$. concretus and other insectivorous species of Meiglyptini. Therefore, natural selection appears to have shaped the jaw apparatus as a whole differently in species with different food types feeding locations, irrespective of their foraging mode. This becomes clear when the development of these structures is considered in species of Meiglyptes and Mulleripicus compared to Hemicircus concretus. These aspects will be further discussed elsewhere based on the results of this study.

\section{Acknowledgments}

The author is very indebted to Martjan Lammertink, who collected the woodpeckers and made them available for me to study in detail. I am very grateful to the curators of the Museum Zoologicum Bogoriense, the Indonesian Institute of Sciences (LIPI), and the Natural History Museum of the Indonesian Institute of Sciences (MZB), Indonesia for the loan of the Picini for anatomical studies. I also thank the curators of the National Museum of Natural History (USNM), Smithsonian Institution, Washington DC, USA for allowing me to visit the collection to study the Picidae.

\section{References}

[1] R. J. Donatelli, "The jaw apparatus of the neotropical and afrotropical woodpeckers (Aves: Piciformes)," Arqivos de Zoologia, vol. 33, pp. 1-70, 1996.

[2] H. Winkler and D. A. Christie, "Family Picidae (woodpeckers)," in Handbook of the Birds of the World, Vol. 7: Jacamars to Woodpeckers, J. del Hoyo, A. Elliot, and J. Sargatal, Eds., pp. 296-555, Lynx Editions, Barcelona, Spain, 2002.

[3] J. J. Baumel, A. S. King, J. E. Breazile, and H. E. Evans, Nomina Anatomica Avium, Academic Press, London, UK, 1993.

[4] J. J. Baumel and L. M. Witmer, "Osteologia," in Nomina Anatomica Avium, J. Baumel, A. S. King, J. E. Breazile, and H. E. Evans, Eds., pp. 45-132, Academic Press, London, UK, 1993.

[5] R. J. Donatelli, “The jaw musculature of the Meiglyptini (Aves: Piciformes: Picidae)," Acta Zoologica (Stockholm) (In press).

[6] E. Höfling and J. P. Gasc, "Biomécanique du crâne et du bec chez Ramphastos (Aves, Ramphastidae)," Gegenbaurs Morphologisches Jahrbuch, vol. 130, pp. 125-147, 1984.

[7] P. J. K. Burton, "Anatomy and evolution of the feeding apparatus in the avian orders Coraciiformes and Piciformes," Bulletin of the British Museum of Natural History, Zoology, vol. 47, pp. 331-443, 1984.

[8] W. J. Bock, "Functional and evolutionary morphology of woodpeckers," Ostrich, vol. 70, no. 1, pp. 23-31, 1999. 
[9] W. H. Burt, "Adaptative modifications in the woodpeckers," University of California Publications in Zoology, vol. 32, pp. 455-524, 1930.

[10] M. Jollie, "The head skeleton of the chicken and remarks on the anatomy of this region in other birds," Journal of Morphology, vol. 100, pp. 389-436, 1957.

[11] R. J. Donatelli, "Cranial osteology and myology of the jaw apparatus in the Galbulidae (Aves: Piciformes)," Arqivos de Zoologia, vol. 32, pp. 1-32, 1992.

[12] M. C. Pascotto, E. Höfling, and R. J. Donatelli, "Cranial osteology of Coraciiformes (Aves) [Osteologia craniana de Coraciiformes (Aves)]," Revista Brasileira de Zoologia, vol. 23, no. 3, pp. 841-864, 2006.

[13] H. Hofer, "Untersuchungen uber den Bau des Vögelschadels besonders über den der Spechte und Steinhuhner," Zoologische Jahrbücher. Abteilung für Anatomie und Ontogenie der Tiere, vol. 69, pp. 1-158, 1945.

[14] W. J. Bock, "Kinetics of the avian skull," Journal of Morphology, vol. 114, pp. 1-52, 1964.

[15] E. M. S. J. van Gennip, “The osteology, arthrology and myology of the jaw apparatus of the Pigeon (Columba livia L.)," Netherlands Journal of Zoology, vol. 36, pp. 1-46, 1986.

[16] J. Rooth, "On the correlation between the jaw muscles and the structure of the skull in Columba palumbus palumbus L." Proceedings of the Koninklijke Nederlandse Akademie van Wetenschappen, vol. 56, pp. 251-264, 1953.

[17] R. L. Merz, "Jaw musculature of the mourning and whitewinged doves," University of Kansas Publications, Museum of Natural History, vol. 12, pp. 521-551, 1963.

[18] H. Morioka, "Jaw musculature of swifts (Aves, Apodidae)," Bulletin of the National Museum of Natural Science, vol. 17, pp. 1-16, 1974. 

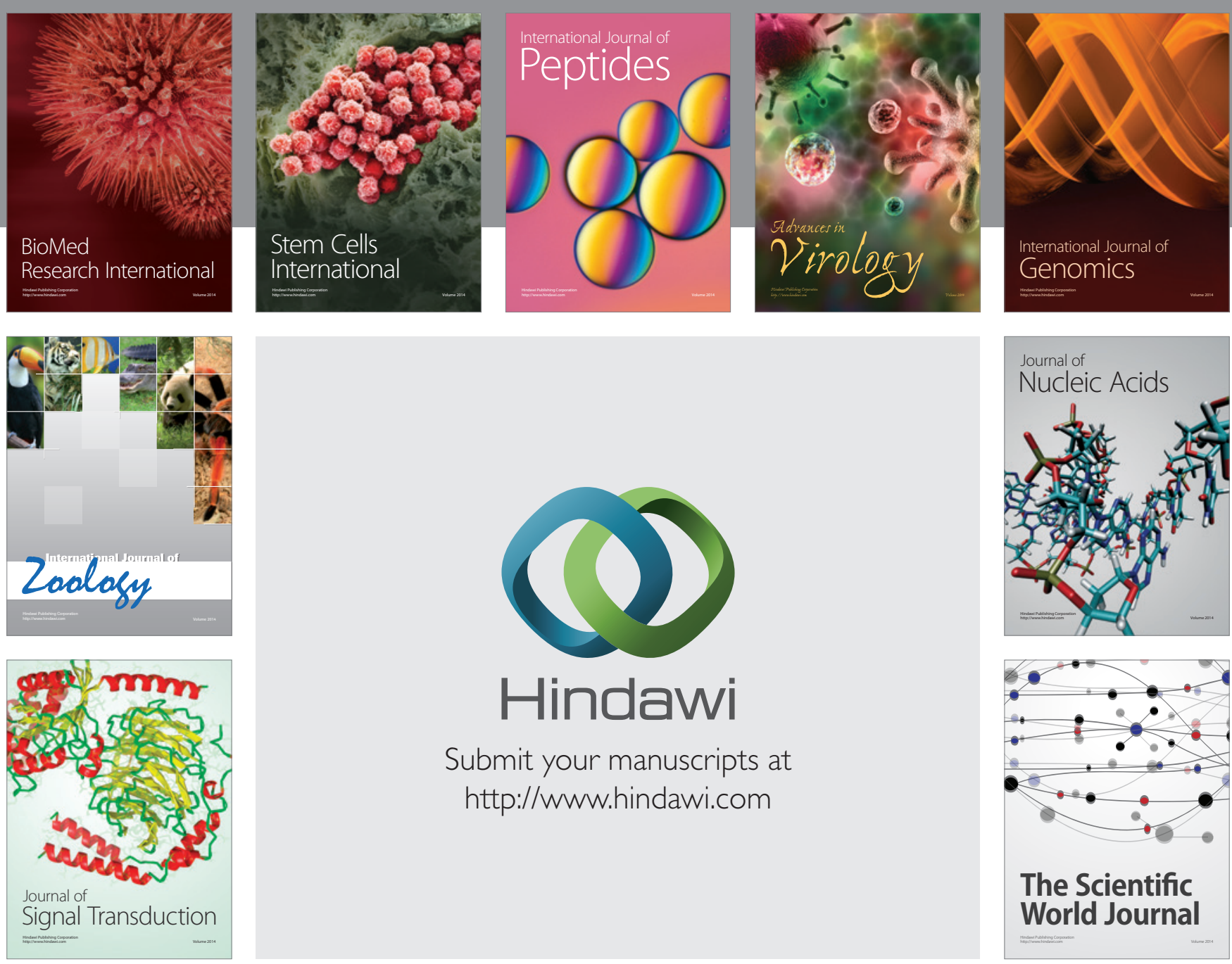

Submit your manuscripts at

http://www.hindawi.com
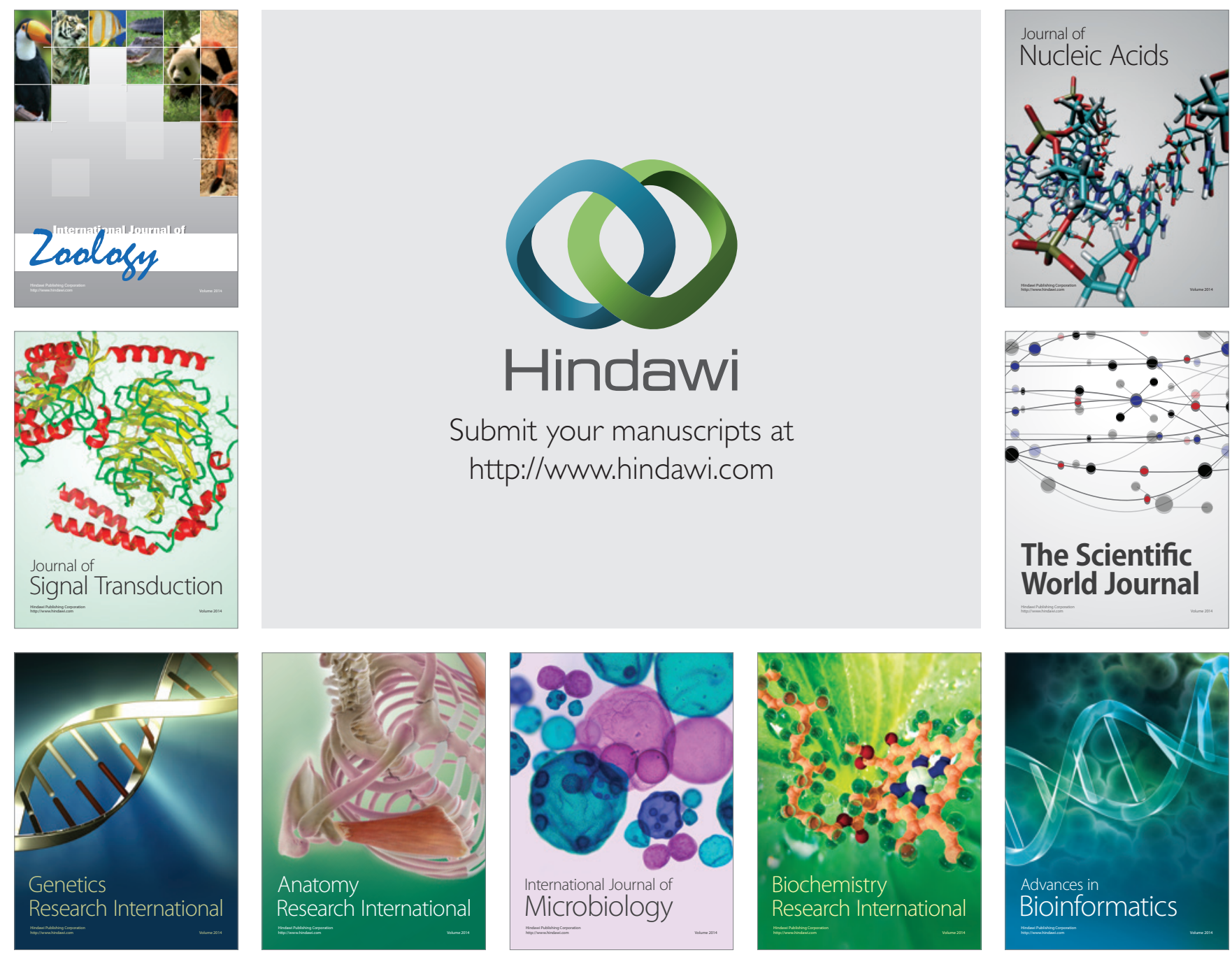

The Scientific World Journal
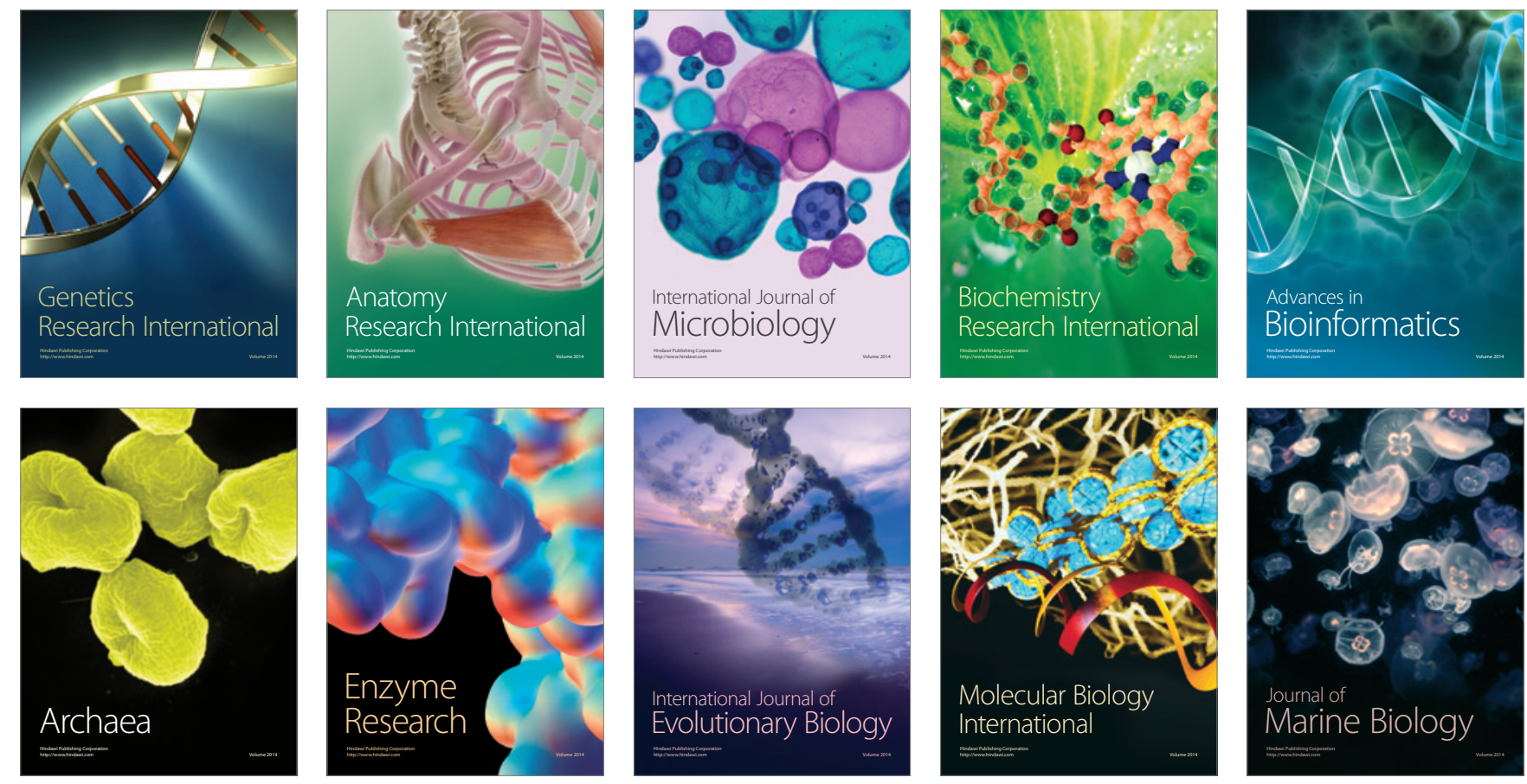